\title{
Stabilisasi Sistem Pendulum Kereta Menggunakan Kontroler Linear Quadratic Gaussian
}

\author{
Devina Rahmawati, Trihastuti Agustinah \\ Departemen Teknik Elektro - Fakultas Teknologi Elektro Institut Teknologi Sepuluh Nopember \\ E-mail: devinarahmawati39@gmail.com, trihastuti@elect-eng.its.ac.id
}

\begin{abstract}
Abstrak-Sistem pendulum kereta merupakan salah satu sistem nonlinear dan tidak stabil. Permasalahan kontrol yang terdapat pada sistem pendulum kereta adalah stabilisasi, tracking dan swing-up. Pada makalah ini akan membahas mengenai stabilisasi sistem pendulum kereta dengan menggunakan metode Linear Quadratic Gaussian. Permasalahan dalam desain sistem kontrol pada sistem pendulum kereta ini yaitu bagaimana cara untuk mengatasi noise dan disturbance yang terjadi pada plant sistem pendulum kereta dengan menstabilkan posisi pendulum agar tetap pada posisi equilibriumnya dan posisi kereta mampu mengikuti sinyal referensi yang diberikan. Model nonlinear dari sistem pendulum kereta dilinearisasikan sehingga akan dihasilkan model linear dari sistem. Dari pemodelan linear tersebut dirancang sebuah kontroler state feedback menggunakan metode optimal Linear Quadratic Gaussian. Gain state feedback dan gain integral diperoleh dengan menggunakan metode Linear Quadratic Regulator. Hasil simulasi menunjukkan bahwa posisi kereta dapat mengikuti sinyal referensi dengan tetap mempertahankan sudut pendulum di sekitar 0 radian. Sedangkan untuk pemberian nilai varian noise yang masih dapat diterima oleh sistem sebesar 0,0005 dengan nilai Mean Square Error (MSE) sebesar 0,0245 untuk posisi kereta dan 0,0156 untuk posisi pendulum.
\end{abstract}

Kata Kunci-Sistem Pendulum Kereta, Linear Quadratic Gaussian (LQG), Linear Quadratic Regulator (LQR), Sistem Servo Tipe 1, Kalman Filter.

\section{PENDAHULUAN}

$\mathrm{S}$ EIRING dengan perkembangan teknologi dan semakin banyaknya sistem yang nonlinear maka dibutuhkan kontrol yang tepat agar suatu sistem dapat memberikan respon yang baik. Sistem pendulum kereta merupakan salah satu sistem nonlinear dan tidak stabil.

Permasalahan kontrol yang terdapat pada sistem pendulum kereta adalah stabilisasi, tracking dan swing-up. Stabilisasi merupakan upaya untuk membuat batang pendulum tetap menjaga kestabilannya pada posisi terbalik yaitu pada sudut nol radian. Tracking merupakan upaya yang dilakukan untuk mengontrol posisi kereta mengikuti sinyal referensi yang diberikan. Sedangkan swing-up merupakan upaya yang dilakukan untuk mengayunkan batang pendulum dari posisi awal ke posisi terbalik.

Pada makalah ini permasalahan yang akan diselesaikan yakni mengatur posisi kereta sesuai dengan sinyal referensi step sekaligus menggerakkan batang pendulum dari posisi awal ke posisi equilibrium dan menstabilkannnya. Beberapa metode telah dikembangkan untuk mendapatkan solusi dari masalah tracking, diantaranya dengan menggunakan metode Fuzzy-Optimal [1] dan Fuzzy model Following [2]. Penyelesaian permasalahan dari sistem pendulum kereta menggunakan metode LQG (Linear Quadratic Gaussian) diharapkan dapat menghasilkan respon yang baik dan dapat mengatasi noise dan disturbance yang terdapat pada plant. Dan juga pada [3] dikembangkan kontrol tracking dengan menggunakan desain Sistem Servo Tipe 1 dengan plant tanpa integrator yang diharapkan agar plant dapat mengikuti sinyal referensi yang diberikan. Sistem pendulum kereta yang nonlinear perlu direpresentasikan terlebih dahulu kedalam model linear agar lebih mudah dalam pengendaliannya.

\section{TINJAUAN PUSTAKA}

\section{A. Sistem Pendulum Kereta [4]}

Sistem pendulum kereta merupakan salah satu benchmark yang merupakan plant khusus yang dapat digunakan untuk mempelajari metode-metode yang dapat digunakan untuk plant nonlinear. Oleh sebab itu untuk dapat mengontrol sistem yang bersifat nonlinear tersebut diperlukan teknik kontrol tertentu yang dapat menstabilkan dan membuat batang pendulum tetap pada posisi equilibriumnya yaitu pada sudut nol radian.

Sistem pendulum kereta merupakan sistem fisik yang terdiri dari sepasang batang pendulum yang bersumbu pada kedua sisi kereta. Kereta bebas bergerak pada arah horizontal sedangkan batang pendulum hanya dapat bergerak pada arah vertikal. Sebuah gaya kontrol $u$, sejajar dengan lintasan yang diterapkan pada kereta. Massa kereta dilambangkan dengan $m_{c}$ dan massa pendulum dengan $m_{p}$. Sedangkan $l$ adalah jarak antara sumbu rotasi dengan pusat massa sistem. $J$ adalah momeninersia dari sistem pendulum kereta yang berhubungan dengan pusat massa. Gambar 1 menunjukkan skematis dari sistem pendulum kereta.

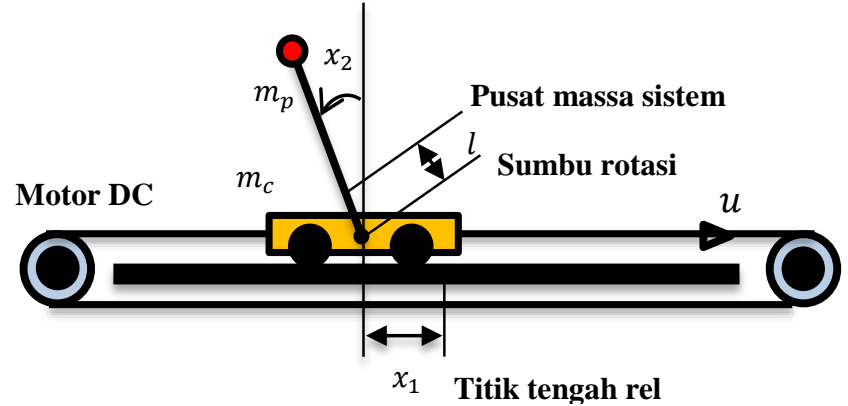

Gambar 1. Skematis Sistem Pendulum Kereta [4]

Pada Gambar 2 menunjukkan gaya-gaya yang bekerja pada sistem pendulum kereta. Melihat free body diagram pada Gambar 2 akan dapat diketahui gaya-gaya yang bekerja pada bidang horizontal dan vertikal. Gaya-gaya yang bekerja pada bidang horizontal adalah gaya kontrol $u$ dan gaya gesek $T_{c}$. Massa keseluruhan sistem $(m)$ merupakan penjumlahan massa kereta $\left(m_{c}\right)$ dan massa pendulum $\left(m_{p}\right)$. Sedangkan gaya-gaya yang bekerja pada bidang vertikal yaitu gaya normal $V$ dan gaya berat sistem $\left(m_{c}+m_{p}\right) g$.

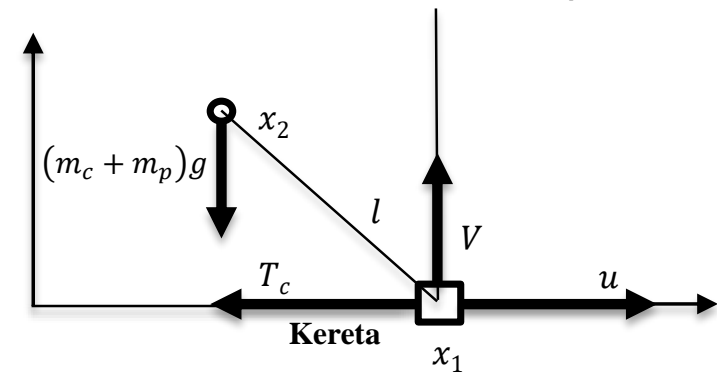

Gambar 2. Gaya-gaya yang Bekerja pada Sistem Pendulum Kereta [4] 
Sistem pendulum kereta memiliki empat state yaitu $x_{1}, x_{2}, x_{3}, x_{4}$, dimana

$x_{1}$ : posisi kereta diukur dari titik tengah rel

$x_{2}$ : sudut batang pendulum terhadap sumbu vertikal, diukur berlawanann dengan arah jarum jam $\left(x_{2}=0\right.$ menyatakan batang pendulum pada posisi terbalik)

$x_{3}$ : kecepatam kereta

$x_{4}$ : kecepatan sudut batang pendulum

$T_{c}$ menyatakan gaya gesekan gerak kereta pendulum. $D_{p}$ adalah momen gesek (moment of friction) pada pergerakan sudut pendulum, proporsional untuk kecepatan sudutnya adalah $D p=f p x 4$. Gaya reaksi pada kereta $V$ berarah vertikal. Koordinat arah horizontal pada pusat massa sama dengan $\left(x_{1}-l \sin x_{2}\right)$ dan arah vertikalnya (1 $\cos x_{2}$ ). Sesuai dengan hukum kedua Newton, persamaan gerak dapat ditulis menjadi:

$u-T_{c}=\left(m_{c}+m_{p}\right)\left(x_{1}-l \sin x_{2}\right)^{\prime \prime}$

$V-\left(m_{c}+m_{p}\right) g=\left(m_{c}+m_{p}\right)\left(1 \cos x_{2}\right) "$

$\left(u-T_{c}\right) l \cos x_{2}+V l \sin x_{2}-D_{p}=J x_{2}{ }^{\prime \prime}$

Persamaan (1) dan (2) menyatakan gerak translasi dari pusat massa sistem, sedangkan Persamaan (3) menyatakan gerak rotasi sistem terhadap pusat massa sistem. Model matematika dalam bentuk persamaan state dituliskan sebagai berikut:

$x_{1}{ }^{\prime}=x_{3}$

$x_{2}{ }^{\prime}=x_{4}$

$x_{3}{ }^{\prime}=\frac{a\left(u-T_{c}-\mu x_{4}{ }^{2} \sin x_{2}\right)}{\left(J+\mu l \sin ^{2} x_{2}\right)}+\frac{l \cos x_{2}\left(\mu \mathrm{g} \sin x_{2}-f_{p} x_{4}\right)}{\left(J+\mu l \sin ^{2} x_{2}\right)}$

$x_{4}{ }^{\prime}=\frac{\left(u-T_{c}-\mu x_{4}{ }^{2} \sin x_{2}\right) l \cos x_{2}+\mu \mathrm{g} \sin x_{2}-f_{p} x_{4}}{J+\mu l \sin ^{2} x_{2}}$

dengan

$a=l^{2}+\frac{J}{m_{c}+m_{p}}$

$\mu=\left(m_{c}+m_{p}\right) l$

Model tersebut dilinearisasi dengan menggunakan metode Jacobian sehingga didapatkan model state space.

\section{B. Linear Quadratic Gaussian ( $L Q G)$}

Linear Quadratic Gaussian (LQG) merupakan salah satu metode kontrol optimal. Pada dasarnya kontrol optimal merupakan salah satu metode kontrol yang modern. Kontrol optimal memberikan solusi untuk menentukan nilai sinyal kontrol $u$ yang optimal dengan nilai dari indeks performansi yang minimum. Indeks performansi adalah kuantitatif performansi dari suatu sistem, penekanan diberikan pada spesifikasi sistem yang diprioritaskan, misalnya error dan sinyal kontrol. Linear Quadratic Gaussian (LQG) sendiri merupakan perkembangan dari konsep Linear Quadratic Regulator (LQR) yakni dengan menambahkan estimator (Kalman Filter) yang berfungsi untuk menyaring noise. Pengaruh noise pada kontroler menyebabkan tidak optimalnya sinyal kontrol pada aktuator, sehingga untuk mengoptimalkan input pada proses $(u)$ diperlukan penguat kontroler regulator $(K)$ dan penguat estimator Kalman filter (L).

Linear Quadratic Regulator (LQR) merupakan metode kontrol optimal yang bertujuan untuk membuat semua state sistem dari nilai sembarang menjadi sama dengan 0 . Untuk mendapatkan respon yang optimal maka perlu dicari nilai gain $K$. Berikut merupakan diagram blok dari LQR yang ditunjukkan pada Gambar 3.

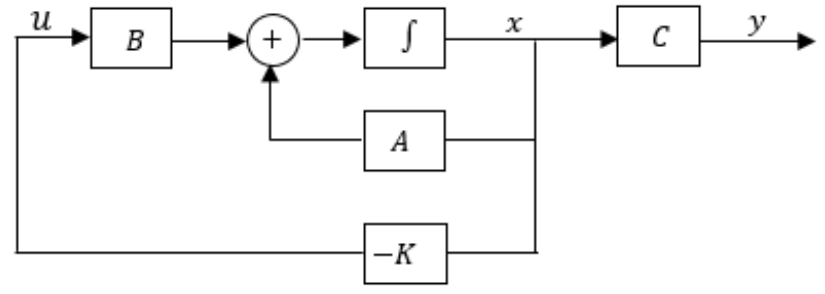

Gambar 3. Diagram Blok Linear Quadratic Regulator [5]
Apabila dietahui persamaan plant seperti pada Gambar 3 untuk mendesain $\mathrm{LQR}$ dengan

$u(t)=-K(t) x(t)$

dimana $K$ merupakan matriks gain state feedback dan $u(t)$ tidak memiliki batasan (unconstrained). Maka akan didapatkan persaan sebagai berikut:[5]

$\dot{\mathrm{x}}=A x-B K x=(A-B K) x$

dengan indeks performansi yang digunakan [5]

$J\left(t_{0}\right)=\frac{1}{2} \int_{t_{0}}^{T}\left(x^{T} Q(t) x+u^{T} R(t) u\right) d t$

variabel $x$ adalah vektor state orde ke $\mathrm{n}, u$ adalah vektor kontrol orde n, $A$ adalah matriks state $n \times n, B$ adalah matriks state $r \times r$. Nilai matriks pembobot $Q$ dan $R$ ditentukan melalui trial and error dengan syarat bahwa kedua matriks tersebut harus diagonal. Matriks $Q$ merupakan matriks positif semidefinit dan matriks $R$ merupakan matriks positif definit. Selain itu pedoman untuk pemilihan matriks pembobot $Q$ dan $R$ adalah sebagi berikut:

1. Semakin besar nilai $Q$, maka akan semakin besar harga elemen penguatan $K$ sehingga mempercepat sistem untuk mencapai keadaan stabil.

2. Semakin besar harga $R$, maka akan memperkecil harga penguatan $K$ dan memperlambat keadaan tunak.

Kalman filter merupakan estimator yang dapat melakukan estimasi state dari output yang terdapat pada plant yang memiliki noise. Dengan kata lain bahwa Kalman filter dapat menghilangkan noise. Berikut merupakan diagram blok dari Kalman filter dengan disturbance pada plant dan noise pada pengukuran.

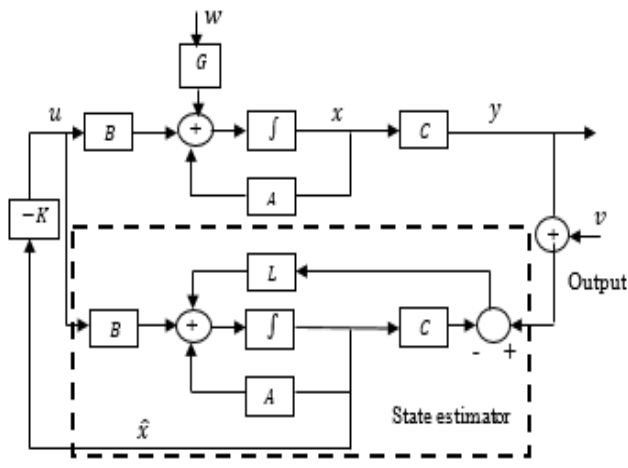

Gambar 4. Diagram Blok Kalman Filter [6]

Plant linear yang digunakan seperti pada Gambar 4 dengan kontrol state feedback sebagai berikut:

$u=-K x$

maka diperoleh bentuk persamaan sistem closed loop sebagai berikut:

$\dot{x}=A x+B u+G w$

$y=C x+v$

dengan $A, B$ dan $G$ merupakan matriks dengan dimensi yang sesuai. Sedangkan sinyal $w(t)$ merupakan disturbance yang tidak diketahui sebagai gangguan pada plant dan sinyal $v$ merupakan noise pada pengukuran. Keduanya merupakan proses acak gaussian white noise. Sehingga untuk kondisi awal yang diasumsikan $x(0)$ memiliki nilai mean $\bar{x}_{0}$ dan kovarian $P_{0}$, dapat dituliskan

$\tilde{x}(0) \approx\left(\tilde{x}_{0}, P_{0}\right)$

Dapat diasumsikan bahwa disturbance pada plant dan noise di pengukuran sebagai berikut:

$w(t) \sim(0, Q) \quad ; Q \geq 0$

$v(t) \sim(0, R) \quad ; R>0$

\section{Desain Sistem Servo Tipe 1 [7]}

Sistem kontrol tracking berbasis servo tipe 1 dirancang untuk mengontrol posisi kereta dari sistem pendulum kereta sehingga dapat mengikuti sinyal referensi yang diberikan sekaligus menjaga keseimbangan batang pendulum dari sistem agar tetap pada posisi terbalik yaitu pada posisi equilibriumnya. Pencarian matriks gain kontrol $K$ dan gain integrator $K_{i}$ dapat dilakukan dengan menggunakan teknik pole placement maupun LQR. Sistem pendulum kereta merupakan sistem tanpa integral. Prinsip dari 
sistem servo tipe 1 adalah adanya integral seperti yang diperlihatkan diagram blok pada Gambar 5. Pada diagram blok Gambar 5 dapat diketahui bahwa suatu sistem mempunyai bentuk persamaan sebagai berikut:

$\dot{x}=A x+B u$

$y=C x$

Persamaan sinyal input kontrol dan error masing-masing dinyatakan dalam persamaan berikut ini.

$u=-K x+k_{i} \xi$

$\dot{\xi}=r-y=r-C x$

dengan:

$$
\begin{aligned}
& x=\text { State } \text { vektor pada plant } \\
& u=\text { Sinyal kontrol } \\
& y=\text { Sinyal } \text { output } \\
& \xi=\text { Output integrator } \\
& r=\text { Sinyal referensi (fungsi step) }
\end{aligned}
$$

Dari persamaan sistem yang telah diketahui kemudian digabungkan dengan Persamaan (22) maka diperoleh sistem augmented sebagai berikut:

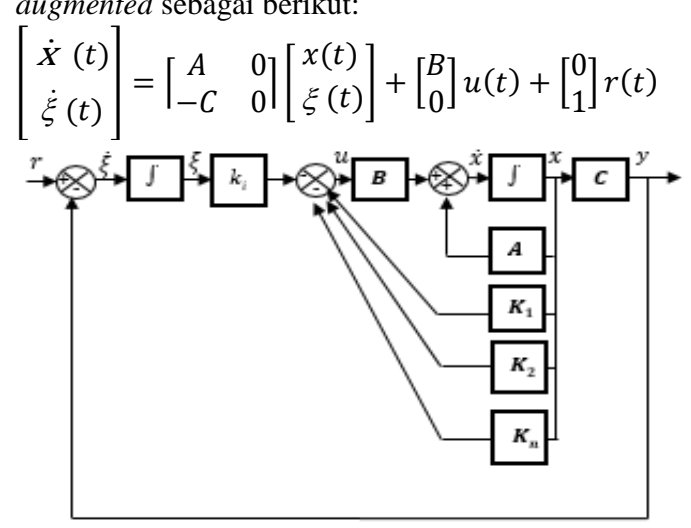

Gambar 5. Struktur Sistem Servo Tipe 1 dengan plant tanpa Integrator [7]

\section{PERANCANGAN SISTEM}

Perancangan sistem sebuah kontroler state feedback menggunakan metode optimal Linear Quadratic Gaussian (LQG) dapat dilihat pada Gambar 6.

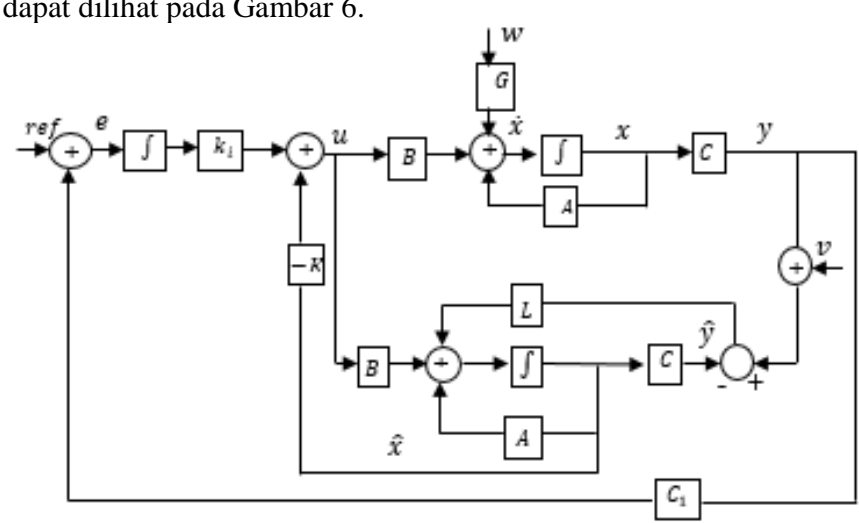

Gambar 6. Diagram Blok Kontrol LQG Sistem Servo

Pada perancangan simulasi plant sistem pendulum kereta akan dijelaskan mengenai pemodelan sistem pendulum kereta menggunakan Simulink MATLAB. Selanjutnya akan dilakukan linearisasi model matematika sistem pendulum kereta di titik kerja yang diambil yaitu sudut 0 atau 0 radian. Persamaan (4), Persamaan (5), Persamaan (6) dan Persamaan (7) dapat dilinearisasikan dengan mendefinisaikan terlebih dahulu nilai $f(x)$ dan $h(x, u)$. Selanjutnya dilakukan penurunan persamaan sehingga dihasilkan elemen-elemen dari matriks $A$ dan $B$. Dari hasil penurunan tersebut nilai $x_{1}$ tidak berpengaruh, oleh karena itu dilakukan linearisasi titik kerja pada $x_{2}$ yaitu 0 derajat atau 0 radian. Sedangkan untuk sinyal kontrol $u=0$. Sehingga persamaan state space dari linearisasi yang dihasilkan sebagi berikut:

$x=\left[\begin{array}{llll}0 & 0 & 0 & 0\end{array}\right]^{T} \quad$ dan $u=0$ diperoleh

$$
A=\left[\begin{array}{cccc}
0 & 0 & 1 & 0 \\
0 & 0 & 0 & 1 \\
0 & 0,2525 & 0 & -0,0001 \\
0 & 15,0319 & 0 & -0,0079
\end{array}\right] ; B=\left[\begin{array}{c}
0 \\
0 \\
0,8272 \\
1,2377
\end{array}\right]
$$

Setelah memperoleh hasil linearisasi di sekitar titik 0 yang berupa state space, selanjutnya dapat ditentukan nilai gain Kalman $K$ dan gain integrator $K_{i}$. Menentukan gain Kalman $K$ dan gain integrator $K_{i}$ dibutuhkan penetuan lima nilai pada diagonal matriks pembobot $Q$ dikarenakan terdapat lima state pada sistem. Pada makalah ini penentuan nilai matriks pembobot $Q$ dan $R$ ditentukan dengan cara trial and error dengan melihat hasil respon yang terbaik. Menggunakan syntax lqr pada MATLAB maka akan diperoleh nilai gain Kalman $K$ dan gain integrator $K_{i}$ sebagai berikut:

$K=\left[\begin{array}{llll}-41,7795 & 119,5742-27,8509 & 30,8106\end{array}\right]$

$K_{i}=[22,3607]$

Menentukan gain filter dengan menggunakan metode pole placement dapat dilakukan dengan melihat peletakan pole dominan. Sedangkan untuk pole state yang lainnya tidak boleh lebih kecil dari pole dominan. Penentuan pole dominan dapat dicari dengan menggunakan pendekatan respon orde 2 dengan menentukan nilai rasio peredaman $(\zeta)$ dan frekuensi alami tak teredam $\left(\omega_{n}\right)$. Sedangkan untuk penentuan pole pada observer minimal harus lebih cepat untuk respon waktu yang dihasilkannya. Dengan menggunakan program MATLAB dengan syntax place, maka akan diperoleh nilai gain filter $L$ yaitu:

$L=\left[\begin{array}{cc}7,2001 & -0,0148 \\ -0,0039 & 7,9920 \\ 12,9504 & 0,1976 \\ -0,0149 & 30,9283\end{array}\right]$

Selain itu nilai gain filter juga dapat ditentukan dengan menggunakan metode Kalman Filter. Sistem ini memiliki nilai covariance noise yaitu $Q_{n}$ dan $R_{n}$, dimana nilai-nilai tersebut ditentukan dengan trial and error. Penentuan matriks $Q_{n}$ dan $R_{n}$ memiliki syarat yaitu matriks tersebut merupakan matriks simetris, dengan melihat hasil respon yang terbaik. Dengan menggunakan program MATLAB dengan syntax Kalman, maka akan diperoleh nilai gain filter $L$ yaitu:

$L=\left[\begin{array}{cc}1,5332 & 10,2198 \\ -7,4878 & 22,6475 \\ 2,9915 & 80,7253 \\ -47,5420 & 175,3561\end{array}\right]$

\section{HASIL SIMULASI SISTEM DAN ANALISA}

Simulasi yang pertama dilakukan yaitu simulasi tanpa pemberian noise dan disturbance. Simulasi dilakukan dengan beberapa metode yaitu pole placement dan Kalman filter. Pada Gambar 7 merupakan hasil simulasi dengan metode pole placement dimana respon posisi kereta yang dihasilkan memiliki overshoot sebesar -0,31 meter untuk posisi kereta yang belum terestimasi dan $-0,41$ meter untuk posisi kereta yang telah terestimasi. Waktu yang dibutuhkan oleh posisi kereta untuk dapat mengikuti sinyal referensi setelah 6,5 detik. Sedangkan respon posisi pendulum sebelum tersetimasi mengalami overshoot sebesar $-0,32$ rad dan posisi pendulum setelah terestimasi memiliki overshoot sebesar $-0,36$ radian. Waktu yang diperlukan posisi pendulum mencapai sudut 0 radian yaitu setelah 4 detik. Hasil sinyal kontrol memiliki overshoot sebesar -19 Newton. Hasil simulasi dengan metode Kalman filter dapat dilihat pada Gambar 8 respon posisi kereta yang dihasilkan memiliki overshoot sebesar $-0,2$ meter untuk posisi kereta yang belum terestimasi dan overshoot sebesar -0,39 meter untuk posisi kereta yang telah terestimasi. Sedangkan waktu yang dibutuhkan oleh posisi kereta untuk dapat mengikuti sinyal referensi setelah 4,5 detik. Hasil respon posisi pendulum sebelum tersetimasi mengalami overshoot sebesar -0,38 rad dan posisi pendulum setelah terestimasi memiliki overshoot sebesar -0,4 radian. Waktu yang diperlukan posisi pendulum untuk mencapai sudut 0 radian yaitu setelah 3,5 detik. Sinyal kontrol memiliki overshoot sebesar -38 Newton.

Selanjutnya simulasi yang akan dilakukan yaitu dengan pemberian varian noise dan varian disturbance. Simulasi dengan 
noise dilakukan dengan dua metode yaitu pole placement dan Kalman filter. Simulasi dilakukan dengan penggunaan varian disturbance yaitu 10\%, 30\% dan 50\% dari nilai inisial kondisi sudut pendulum yaitu $0,03,0,09$ dan 0,15 . Hasil respon dari posisi kereta, posisi pendulum dan sinyal kontrol yang dihasilkan untuk kedua metode tersebut tetap dapat mengikuti respon yang diinginkan seperti terlihat pada Gambar 9 dan Gambar 10.

Setelah itu dilakukan simulasi disturbance dengan pemberian varian noise yaitu 0,0002 dan 0,0005. Hasil respon dari kedua metode dapat dilihat pada Gambar 11 dan Gambar 12.

Pada Gambar 11 dan Gambar 12 respon posisi kereta yang dihasilkan masih dapat teratasi oleh sistem. Sedangkan untuk posisi pendulum yang dihasilkan max overshoot respon tidak melebihi dari inisial kondisi awal yang diberikan. Nilai Mean Square Error (MSE) untuk kedua metode simulasi tersebut dapat dilihat pada Tabel 1 dan Tabel 2.

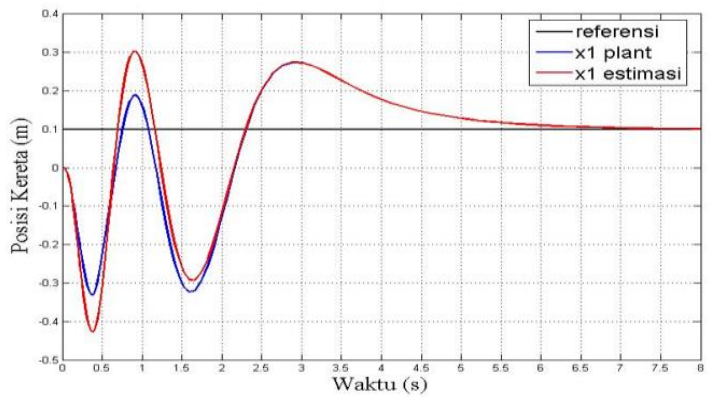

(a) Posisi Kereta

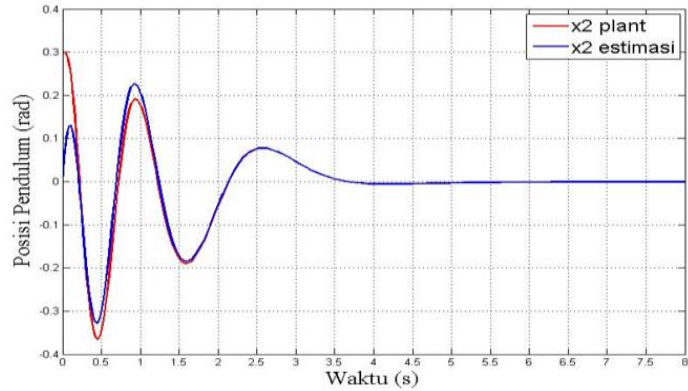

(b) Posisi Pendulum

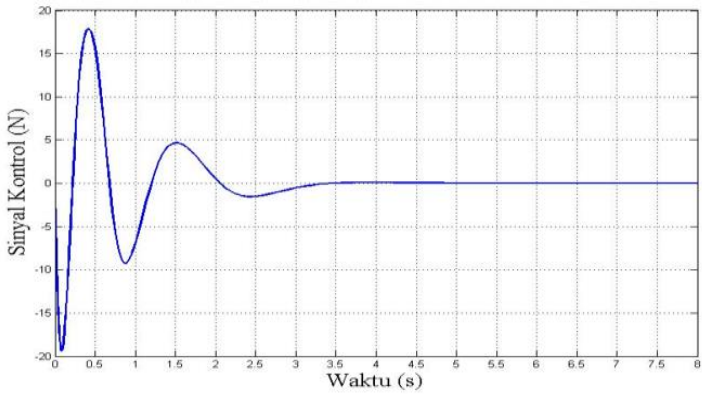

(c) Sinyal Kontrol

Gambar 7. Simulasi Tanpa Noise dan Disturbance Menggunakan Metode Pole placement

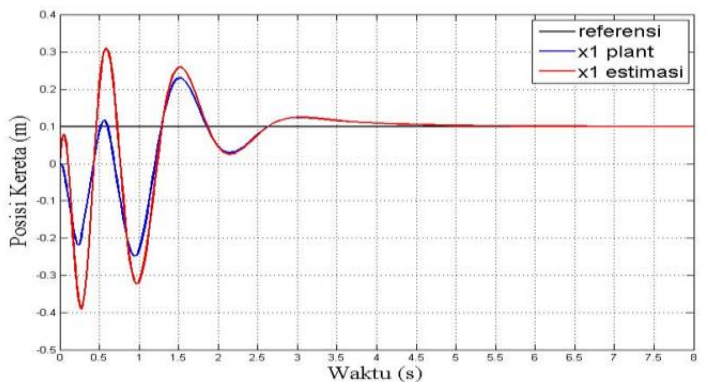

(a) Posisi Kereta

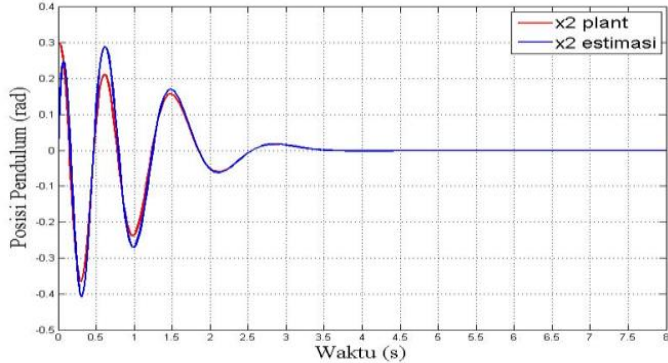

(b) Posisi Pendulum

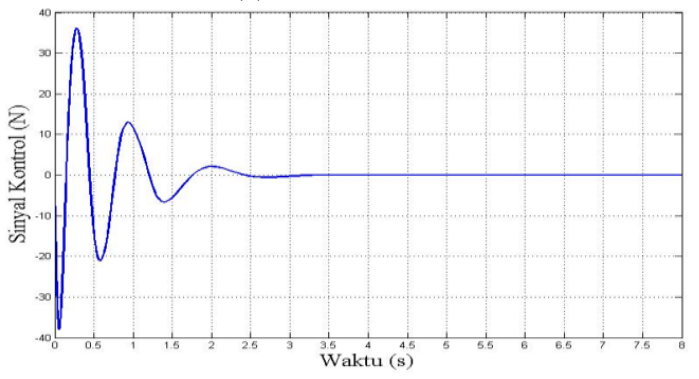

(c) Sinyal Kontrol

Gambar 8. Simulasi Tanpa Noise dan Disturbance Menggunakan Metode Kalman Filter

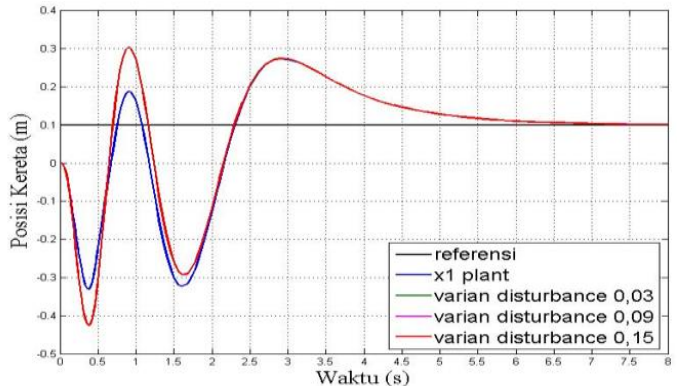

(a) Posisi Kereta

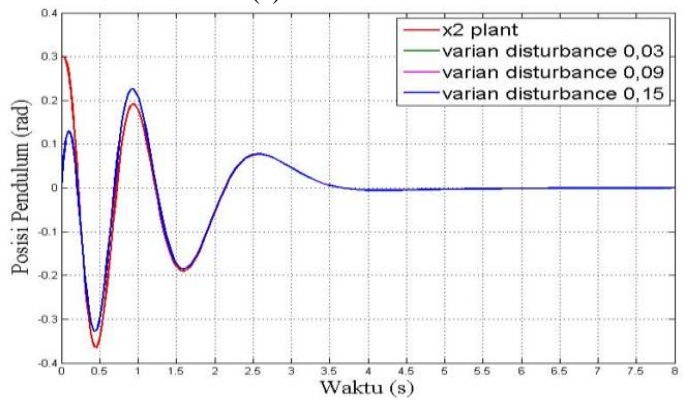

(b) Posisi Pendulum

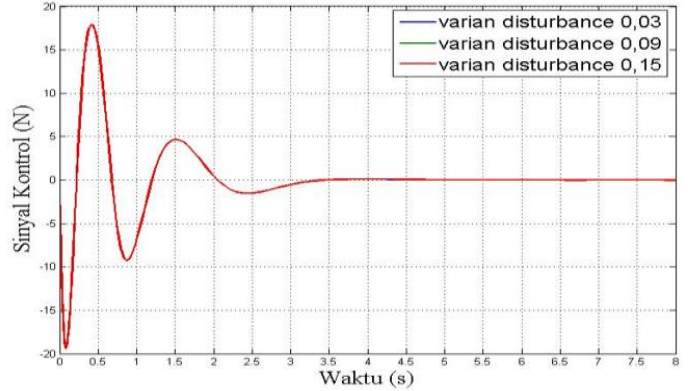

(c) Sinyal Kontrol

Gambar 9. Simulasi dengan Varian Disturbance menggunakan Metode Pole placement 


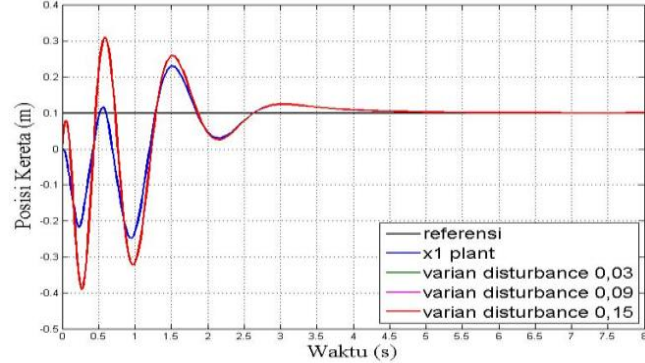

(a) Posisi Kereta

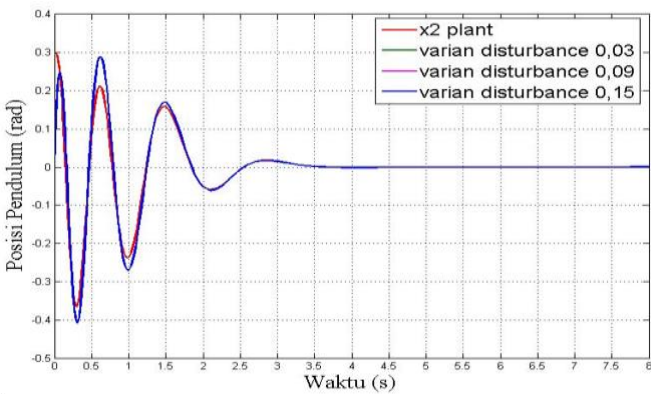

(b) Posisi Pendulum

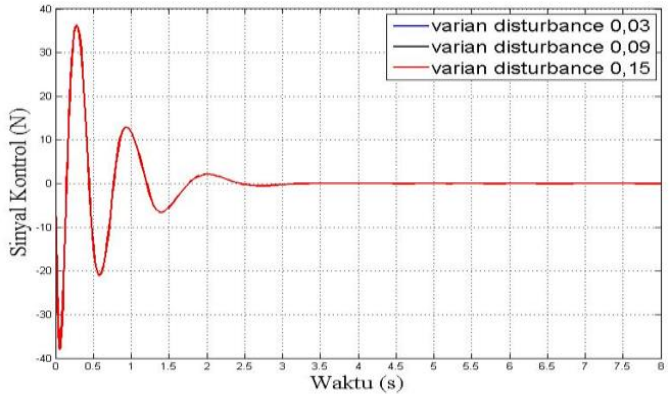

(c) Sinyal Kontrol

Gambar 10. Simulasi dengan Varian Disturbance menggunakan Metode Kalman Filter

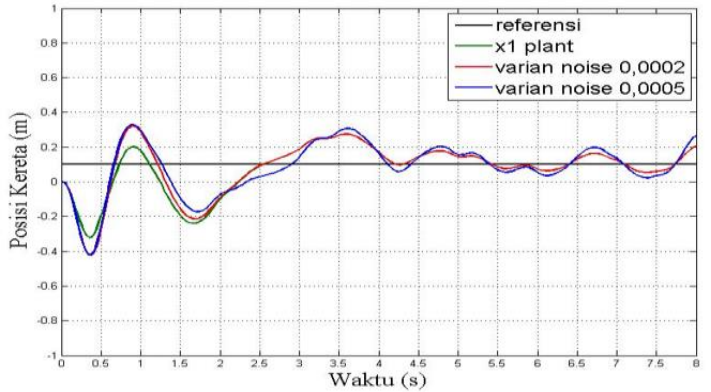

(a) Posisi Kereta

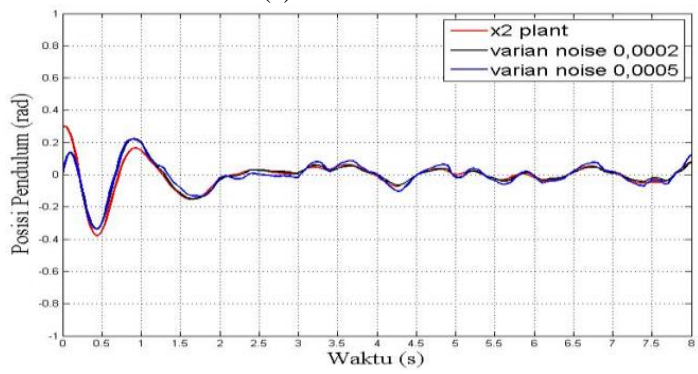

(b) Posisi Pendulum

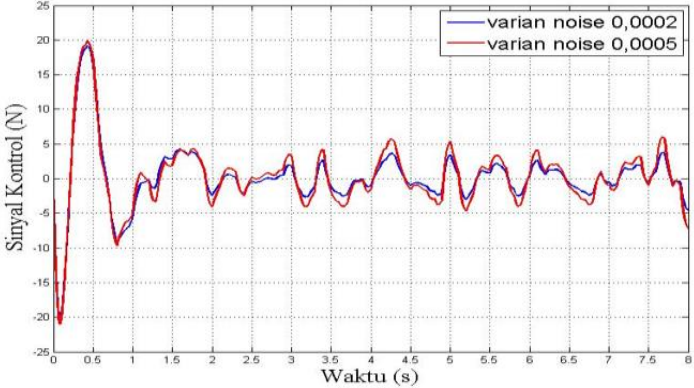

(c) Sinyal Kontrol

Gambar 11. Simulasi Disturbance dengan Varian Noise Menggunakan Metode Pole placement.

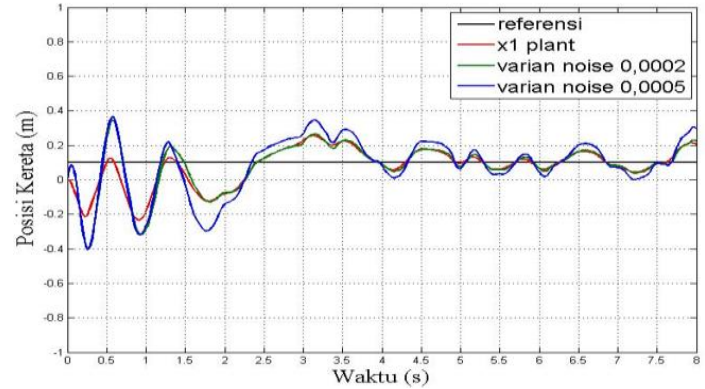

(a) Posisi Kereta

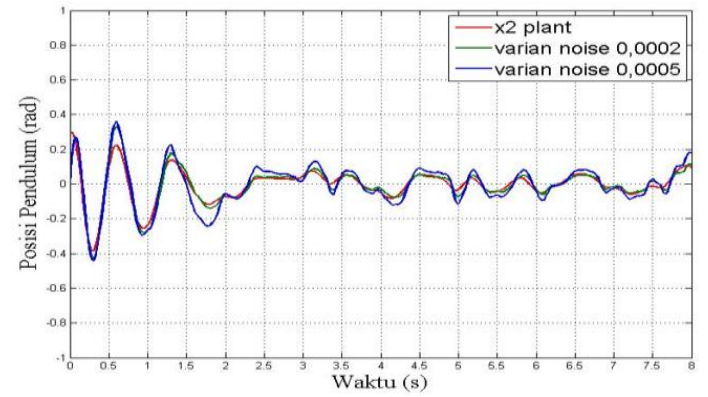

(b) Posisi Pendulum

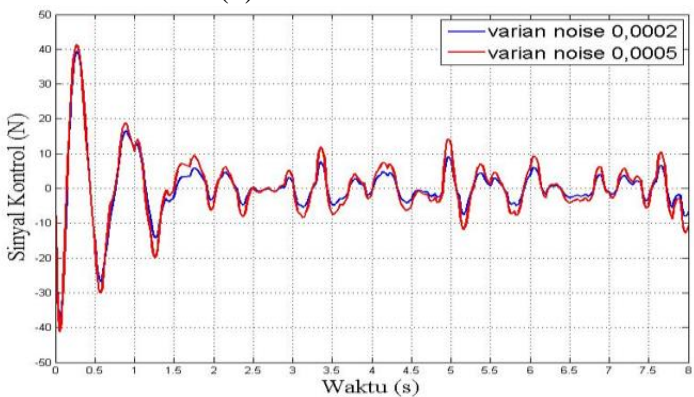

(c) Sinyal Kontrol

Gambar 12. Simulasi Disturbance dengan Varian Noise Menggunakan Metode Kalman Filter

Tabel 1.

Nilai MSE Respon Posisi Kereta dan Posisi Pendulum dengan Varian Noise Metode

Pole placement

\begin{tabular}{ccc}
\hline \hline Varian Noise & Posisi Kereta & Posisi Pendulum \\
\hline 0,0002 & 0,0217 & 0,0071 \\
0,0005 & 0,0217 & 0,0079 \\
\hline
\end{tabular}

Tabel 2.

Nilai MSE Respon Posisi Kereta dan Posisi Pendulum dengan Varian Noise Metode

Kalman Filter

\begin{tabular}{ccc} 
& Kalman Filter & \\
\hline \hline Varian Noise & Posisi Kereta & Posisi Pendulum \\
\hline 0,0002 & 0,0180 & 0,0127 \\
0,0005 & 0,0245 & 0,0156 \\
\hline \hline
\end{tabular}

Dari Tabel 1 dan Tabel 2 menunjukkan bahwa sistem dapat mengatasi noise hingga varian 0,0005 dengan baik. Beberapa varian noise diberikan untuk menunjukkan bahwa semakin besar varian noise maka akan menghasilkan nilai MSE yang semakin besar. 


\section{KESIMPULAN}

Kesimpulan yang dapat diambil diantaranya yaitu:

1. Pada pengujian simulasi tanpa noise dan disturbance dengan menggunakan gain filter $L$ dengan metode pole placement dan kalman filter menunjukkan bahwa posisi kereta dapat mengikuti sinyal referensi dan posisi pendulum dapat menuju 0 radian.

2. Respon posisi pendulum dari penggunaan metode kalman filter tanpa noise dan disturbance lebih baik dibandingkan dengan metode pole placement. Hal tersebut terlihat pada waktu yang dibutuhkan posisi pendulum untuk mencapai sudut 0 radian yaitu setelah 3,5 detik dibandingkan dengan metode pole placement membutuhkan waktu setelah 4 detik.

3. Respon posisi kereta dari penggunaan metode kalman filter tanpa noise dan disturbance lebih baik dibandingkan dengan metode pole placement. Posisi kereta membutuhkan waktu setelah 4,5 detik untuk mengikuti sinyal referensinya dengan menggunakan metode kalman filter sedangkan dengan metode pole placement waktu yang dibutuhkan setelah 6,5 detik.

4. Kontroler LQG dapat diterapkan dan dapat bekerja dengan baik pada sistem pendulum kereta meskipun dengan adanya disturbance pada plant dan noise pada pengukuran.
5. Nilai varian noise yang masih dapat diterima oleh sistem sebesar 0,0005 dengan nilai Mean Square Error (MSE) sebesar 0,0245 untuk posisi kereta dan 0,0156 untuk posisi pendulum.

\section{DAFTAR PUSTAKA}

[1] A. R. Putri, "Kontrol Tracking Fuzzy-Optimal Untuk Sistem Pemdulum Kereta," Institut Teknologi Sepuluh Nopember, 2013.

[2] J. H. Putra, "Kontrol Tracking Fuzzy Menggunakan Model Following Untuk Sistem Pendulum Kereta," Institut Teknologi Sepuuh Nopember, 2015.

[3] H. Indrawati, "Kontrol Fuzzy Takagi-Sugeno Berbasis Sistem Servo Tipe 1 Untuk Sistem Pendulum Kereta," ITS, 2013.

[4] Digital Pendulum: Control in a MATLAB Environment (MATLAB 6.5 Version). Instruments Ltd, 2004.

[5] D. S. Naidu, in Optimal Control System. Pocatello Idaho USA: CRC Press LLC, 1940.

[6] F. L. L. and V. L. Syrmos, in Optimal Control Second Edition. United States of America: A Wiley-Interscience Publication, 1995.

[7] K. Ogata, Modern Control Engineering Third Edition. PrenticeHall International, Inc, 1997. 